\title{
POLÍTICA Y FABRICACIÓN: LA CRÍTICA DE HANNAH ARENDT A LA ONTOLOGÍA POLÍTICA DE PlatÓN
}

\author{
POLITICS AND MANUFACTURE: HANNAH ARENDT'S CRITICISM \\ OF PLATO'S POLITICAL ONTOLOGY
}

Borja Lucena

\begin{abstract}
RESUMEN
El presente artículo trata de acercarse a la crítica de Hannah Arendt a la filosofía política platónica, localizando en ésta la más importante génesis intelectual en la histórica transformación occidental de la política en una técnica del gobierno y el dominio. La autora alemana observó en Platón un desplazamiento crucial que le llevó a considerar la política como un modo de actividad perteneciente al ámbito semántico de la producción de objetos, en vez de al de la acción. En la reformulación de la praxis como una forma de poiesis, el filósofo ateniense abrió el camino para la posibilidad de transformar por completo las relaciones políticas hasta convertirlas en actividades regidas por el modelo jerarquizado y calculable de la fabricación, antes que atenidas a la indeterminación que prima en el espacio horizontal del ágora.
\end{abstract}

PALABRAS CLAVE: Hannah Arendt, Platón, filosofía política, política, fabricación

\begin{abstract}
This article tries to approach Hannah Arendt's criticism to Plato's political philosophy, locating in the last the most important theoretical genesis of the western historical transformation of politics in a technique of government and mastery. The german author noted in Plato a crucial shift that led him to consider politics as a mode of activity belonging to the semantic field of production of objects, and not of action. In the reformulation of praxis as a form of poiesis, the Athenian philosopher opened the possibility of transforming completely all political relations until they become governed by the hierarchical and calculable model of manufacturing rather than by the indeterminacy belonging to the horizontal space of the ágora.
\end{abstract}

KEYWORDS: Hannah Arendt, Plato, political philosophy, politics, manufacture 
Hannah Arendt, a lo largo de una extensa obra dedicada al examen de la realidad política y a la crítica de la categorización filosófica de su complejo ámbito, ofreció notables herramientas conceptuales para desbrozar una relación repleta de malentendidos, de tachaduras y sombras. Ante la presencia continuada de la filosofía política en el marco de la reflexión filosófica occidental, el gesto arendtiano fundamental conmina a realizar un cierto paso atrás, a adoptar una distancia apropiada con la disciplina que permita apreciar qué tipo de relación entre filosofía y política se definió históricamente en ella. Lo que acerca de ello puede revelar la posición fundacional de Platón es de radical importancia. De acuerdo con Arendt, la relación de la filosofía con la política ha estado históricamente marcada, en tanto fue establecida por la creación platónica, por el empeño filosófico de reducir la experiencia de la acción al marco de lo conceptualmente aprehensible, despojándola de sus constantes riesgos: la carencia de previsibilidad, la incapacidad práctica de dominio sobre la complejidad que nutre su acontecer, la novedad que a cada instante amenaza con irrumpir amenazadoramente en el frágil sistema de las relaciones humanas. Lo que Platón muestra, de acuerdo con esto, es una incapacidad propiamente filosófica de comprender lo político, y la consiguiente aspiración a transformar el espacio público de la acción con el fin de asimilarlo a una panoplia de conceptos como los que gobiernan su pensamiento ${ }^{1}$. La tesis mantenida por Arendt desde los años cincuenta del pasado siglo hasta sus

${ }^{1}$ La presencia de Platón en la obra de Arendt es constante. Cabría destacar la centralidad del filósofo ateniense en la crítica al pensamiento político clásico formulada a lo largo de The Human Condition, publicado en 1958. Además, un análisis de las temáticas presentes en sus anotaciones privadas nos da cuenta del reiterado retorno a las fuentes platónicas como modo de desentrañar las aporías de la filosofía política. (Arendt 1998, Arendt 2005 y Arendt 2006). La línea continuada del pensamiento arendtiano viene a parar, una y otra vez, en la constatación del carácter fundador de la reflexión de Platón. La filosofía, en tanto originada en él, es definida como metafísica, y esta posición desata buena parte de los interrogantes afrontados por Arendt: ¿qué tipo de aproximación a la política pertenece por derecho propio a la metafísica? ¿Cómo, desde sus supuestos más íntimos, la metafísica desarbola el campo de los asuntos humanos? ¿Qué es lo mortífero que introduce en esta esfera? En esta dirección, la misma autora llega a confesar que "I have clearly joined the ranks of those who for some time now have been attempting to dismantle metaphysics and philosophy with all its categories" ("He engrosado con claridad las filas de aquellos que, de un tiempo a esta parte, han intentado desmantelar la metafísica y la filosofía junto a todas sus categorías...”). (Arendt 1978, p. 212). Aquí y en lo restante, si no se indica lo contrario, las traducciones son mías. 
últimas obras ${ }^{2}$ es que la filosofía, tal y como fue definida en el originario impulso platónico, es decir, como metafísica, es íntimamente incapaz de comprender la política en tanto política, y por ello todo el abanico de filosofías políticas que han partido de la posición establecida por Platón han resultado ser realmente, antes que acercamientos a sus resortes peculiares, variados intentos de desactivación de lo político mismo. Esta conversión de la política en una actividad teóricofilosófica más, por otra parte, alcanza a abrazar, de acuerdo con Arendt, no sólo los derroteros clásicos de la filosofía, sino incluso las modernas rebeliones filosóficas contra el pensamiento clásico dadas en los siglos XIX y XX: Marx, Nietzsche e, incluso, al menos en sus dimensiones directamente políticas, Heidegger ${ }^{3}$. El hallazgo platónico de un pensar filosófico definido por la aspiración metafísica, o bien fijado en torno a una inversión de ésta, no puede, en suma, dejar de plantear una relación de conflicto y tensión con el ámbito humano de la acción y la vida compartida. La filosofía política es la disciplina habilitada por Platón, no para tratar de comprender lo político, sino para liberar a los hombres del gravoso peso del actuar (Cf. Forti 2001, p. 96). El sintagma "filosofía política", llega a afirmar Arendt, es, en el sentido platónico de la relación, una "contradictio in adjecto" (Arendt 2006, p. 665). En el encuentro entre las ideas filosóficas nacidas de la fundación platónica y las realidades políticas se produjo un choque, una violenta sacudida que se resolvió históricamente en la tentativa especulativa de desarticular el campo de lo político, propiciando la ocultación de sus categorías intrínsecas en favor de esquemas de comprensión capaces de reducir el complejo espacio político

\footnotetext{
${ }^{2}$ Véase, especialmente, la parte primera de su obra póstuma, The Life of the Mind, donde, tratando de apropiarse de una forma nueva de concebir la actividad de pensar, recuerda cómo Platón plasmó un paradigma de pensamiento definido sustancialmente como negación de la acción mundana en general, y, en particular, de la política: "thinking aims at an ends in contemplation, and contemplation is not an activity but a passivity (...)" (“[En Platón] el pensamiento apunta a un fin en la contemplación, y la contemplación no es una actividad, sino una pasividad"). (Arendt 1978, p. 6).

3 Tan poderoso es el influjo de los conceptos platónicos, recuerda Arendt, que incluso aquellos para quienes negar la filosofía clásica fue de primordial importancia permanecieron generalmente presos de las categorías de éste. Así ocurre, de acuerdo con la autora, en el caso de Marx: "En Marx, como en el caso de otros grandes autores del siglo pasado, una actitud en apariencia festiva, desafiante y paradójica encubre la perplejidad de tener que tratar con fenómenos nuevos según los términos de una tradición de pensamiento antigua, fuera de cuya estructura conceptual no se veía posible ninguna clase de pensamiento. Es como si Marx, casi al modo de Kierkegaard y de Nietzsche, mientras usa las herramientas conceptuales de la tradición, tratara desesperadamente de pensar en contra de ella”. (Arendt 1996, p. 44).
} 
a conceptos e ideas afines a los prevalentes en el pensamiento filosófico. Ante la casi absoluta extrañeza de las categorías que configuran la esfera humana de la acción, la filosofía trató de establecer los mecanismos conceptuales de asimilación capaces de ocupar el espacio político y reconducirlo a los cauces familiares de las ideas y las argumentaciones filosóficas. Esta asimilación tuvo, según relata la autora, dos formas principales diversas: la antigua, cuya fundación se encuentra en Platón, y la moderna, cuya culminación se halla en Marx y que, llevando a plenitud la disgregación filosófica del campo político, preparó a su modo la emergencia de las grandes ideologías políticas del siglo $\mathrm{XX}^{4}$.

Consecuentemente, en el presente artículo se tratará de exponer, en alguno de sus multiformes sentidos, el por qué de la incomprensión filosófica del terreno de los asuntos humanos, iluminando alguna de las, por otro lado, brillantes reformulaciones operadas por Platón y aplicadas por él al espacio de la acción. Para ello, se tendrá especialmente en cuenta la perdurabilidad de la aportación platónica en el pensamiento filosófico y político posterior, que puede ser amalgamada en torno a la poderosa metáfora de la fabricación, por la cual se proyecta la imagen de la acción política bajo el prisma de la construcción de objetos, es decir, la poiesis. Con ese objetivo, se intentará confrontar la crítica arendtiana de la filosofía política platónica con textos del filósofo ateniense en lo que poseen de revelador y decisivo, apuntando a una superación de los anclajes conceptuales platónicos presentes en todo pensamiento político que, consciente o inconscientemente, persevera en la maniobra de comprender lo ofrecido en la acción como una forma de fabricación o construcción, sea de una sociedad, un "mundo" o un hombre "nuevos".

Al contemplar la tradición occidental de filosofía política, Hannah Arendt observó cómo su recorrido ha sido completado. El itinerario descrito por su discurrir se cierra formando un círculo. El propósito de hacer de la política una forma de filosofía, propósito con que se inauguró la filosofía política occidental en Platón, es por ella señalado como paradójicamente solidario con el de hacer de la filosofía una forma de intervención política, aquello a lo que alcanzó Marx. Lo importante, en ambos casos, fue la repetida voluntad de alcanzar una cumplida reconciliación de la filosofía y la acción a través de la unificación de sus respectivos campos. Pervive en todo el recorrido de la tradición el proyecto de reducir lo

\footnotetext{
${ }^{4}$ Acerca de Platón y Marx como principio y fin de la tradición de filosofía política, véase: "La tradición y la época moderna" (Arendt 1996, pp. 33-67). Sobre la relación de la filosofía política y las ideologías políticas contemporáneas puede consultarse mi tesis doctoral (Lucena Góngora 2015).
} 
otro, lo filosóficamente inasimilable, a las categorías capaces de explicarlo, de atarlo a sujección, de neutralizarlo. En este terreno, es sabida la apuesta difícil de la autora alemana: levantar un pensamiento filosófico no adverso a la frágil esfera de la acción política, no tendente a su colonización conceptual; aceptar en el vivir humano, como pliegue irremediable, una escisión originaria entre ámbitos extraños, autónomos y, en última instancia, irreconciliables, el pensamiento y la acción, los cuales no pueden en ningún modo ser completamente reconciliados en una síntesis especulativa superior. Al contrario, el itinerario de la filosofía política, en sus principales exponentes, tomó el carácter opuesto de promover una solución definitiva, un acomodo total entre los ámbitos dispersos, desperdigados, de la vida humana. Para ello la filosofía política trató generalmente, no de comprender lo político en su especificidad, sino hacer de la política una filosofía "por otros medios".

¿Cuáles son los recursos que, según Arendt, movilizó la tradición de filosofía política con el fin de reducir la alteridad e imprevisión de lo político a lo filosóficamente representable? ¿Qué estrategias, no necesariamente deliberadas sino a menudo inconscientes, convergieron en ese formidable esfuerzo teórico de desactivación de los riesgos de la acción que constituyó el cuerpo principal del pensamiento político occidental? ¿Qué grado de eficacia demostraron? A todas estas preguntas procura dar respuesta la narración arendtiana de la tradición de filosofía política.

La operación fundamental descrita por la filósofa consistió, de acuerdo con el trazo firme dibujado por Platón, en invertir las categorías internas que configuran la vita activa. Sería excesivamente prolijo desarrollar toda la reflexión arendtiana acerca de los principales modos de la vida activa humana, las diversas formas en que se agrupa todo el campo de la vida práctica. En The Human Condition (Arendt 1998), lugar en el que se extiende acerca de ello, la autora ofrece una división tripartita que distingue tres grupos significativos de actividades: la labor, o aquel ámbito de conducta en el que los seres humanos se aseguran la pervivencia y conservación de las funciones orgánicas; el trabajo, o el tipo específico de "hacer" por el que el hombre se define como homo faber, constructor de un mundo de objetos; la acción, cuyo modelo de comprensión es la práxis tal y como la entendían los griegos, como un modo activo cuyo resultado no reside en un objeto externo al propio actuar, sino en el propio ejercicio o performance de la actividad misma. La fuente de la realidad política es esta última forma, la acción, unida íntimamente, según Arendt, al lenguaje como modo de aparición mutua de los individuos. Para los efectos de este trabajo, nos ceñiremos sobre todo a estas 
dos últimas formas de actividad, el trabajo y la acción, cuya distinción es crucial en relación al mantenimiento de una vida política genuina, y cuya confusión marca la desaparición de la política y su desplazamiento por diversas formas de fabricación, trabajo y organización técnica. La inversión platónica de las categorías del campo de la vida activa no supuso sólo un reordenamiento conceptual de la acción, sino a la vez una inversión de las jerarquía valorativas que la comunican con el resto de actividades humanas: mientras que la aproximación fenomenológica que emplea Arendt sitúa en la acción el punto focal que irradia sentido sobre el abanico de actividades desarrolladas por los hombres — de modo tal que la sola limitación a la labor biológica o al trabajo terminarían por expulsar a la vida humana del ámbito del sentido-, la inversión filosófica del campo práctico hizo de ella la más baja, la más atravesada por el absurdo de las actividades. Una constante del pensamiento filosófico, según el examen arendtiano, ha sido el desprecio de la acción, su depreciación de la capacidad de actuar hasta colocarla en el grado del sinsentido y el ridículo; ya sea en la descripción platónica del ámbito de la pólis como caverna humana de desorientación, ya como tematización marxiana de la acción política como pantalla que cubre el desarrollo necesario de las fuerzas productivas, el espacio político de aparición fue denostado hasta convertirlo en terreno casi privado de significado.

Reescribir la historia de la filosofía desde el punto de vista de la acción conduce a Hannah Arendt, al elegir la perspectiva que parte de uno de los puntos ciegos de la tradición filosófica, a conmover su suelo axiológico. Interpretada desde tal ángulo, la narración que la pensadora alemana compone deja ver el conjunto de tensiones que nutrieron el constituirse de la filosofía como disciplina, y permite hacer visible una continuidad en su desarrollo que, más allá de la divergencia programática entre escuelas y tendencias, traza un hilo que vincula el principio con el final. Desde esa posición, la filosofía deja ver que, además de ser la invención de una forma positiva de vida y pensamiento, tuvo como aglutinante originario el compromiso contra formas o dimensiones de vida antecedentes cuya pervivencia podía, de un modo u otro, constituir una amenaza para la vida filosofante. En este sentido, la experiencia del juicio y condena de Sócrates fue decisiva para la filosofía platónica. La toma de postura ante la política, ante la acción, es, según esto, parte constitutiva de la filosofía históricamente acaecida, y su entero desarrollo permite colegir que ese crucial posicionamiento se tradujo en la amplia mayoría de los casos — comenzando por el poderoso impulso fundador de Platón- en un posicionamiento contra la acción y contra la política. Los grandes filósofos fueron casi unánimes en su actitud de recelo ante la acción, según defiende 
Arendt; sólo algunos pensadores, que, por lo demás, tienden a ser expulsados del relato convencional de la historia de la filosofía, se atrevieron a acercarse al hecho de la acción desde una postura divergente, no teñida por esos "prejuicios" filosóficos contra la política. Entre estos, cabe destacar a Montesquieu, a Cicerón o a Maquiavelo 5 .

Tal y como había formulado Nietzsche al hablar de la "inversión de todos los valores" presente en el nacimiento de la filosofía, Arendt también detecta una inversión que afecta a la ordenación y el significado antropológico de los diferentes modos del "hacer" humano. Lo que, en el seno de la vida griega, formada en el espíritu de los poemas homéricos, era lo más sobresaliente de la vida humana su capacidad para iniciar lo nuevo a través de acciones, proezas y palabras- se convirtió, desde la perspectiva filosófica, en la más dudosa de las actividades ${ }^{6}$. La filosofía, de acuerdo con la máxima de Hegel, vino a la luz como un sentido común vuelto completamente del revés (Cf. Arendt 1978, p. 88), un modo de aprehensión de lo real definido por un estricto juego de oposiciones con respecto a lo dado en la experiencia y el vivir políticos de los griegos. Cabe así avizorar, desde la perspectiva de lo político, un decisivo significado a la contraposición metafísica entre apariencia y esencia. La lucha entre el pensamiento filosófico y el sentido común estableció los polos enfrentados que habían de delimitar la oposición de la filosofía y la acción política como confrontación entre el alejamiento filosófico de lo mundano y la pertenencia humana al mundo. Con su renuncia al sentido común, de acuerdo con esto, la filosofía renunció precisamente a aprehender lo común, que es el mundo compartido por la pluralidad de los hombres, lo que significó una decisiva inhabilitación para comprender la actividad política (Cf. Arendt 1971, pp. 417-446, pp. 424-425). Lo perteneciente a la acción fue cuidadosamente desmontado, rebajado, confundido con actividades extrañas a su dominio, distorsionado por la aplicación de conceptos ajenos a su ámbito. El filosofar dirigido a dar cuenta de la política difuminó las diferencias entre la

\footnotetext{
${ }^{5}$ Véase, por ejemplo, "La tradición de pensamiento político", "La revisión de la tradición por Montesquieu”, "El final de la tradición”, (Arendt 2008, pp. 77-99, 99-107 y 119-131, respectivamente).

6 “Se podrían fácilmente enumerar (...) aquellas experiencias políticas de la humanidad occidental que quedaron sin sitio, podríamos decir que sin un hogar, en el pensamiento político tradicional. Entre ellas se puede encontrar la primigenia experiencia pre-polis de los griegos, tal y como existe en el mundo homérico, con su comprensión de la grandeza de los hechos y las empresas humanas (...)". ("La tradición de pensamiento político", Arendt 2008, p. 81).
} 
acción y otras actividades y estableció como criterio de inteligibilidad, no aquellas medidas pertenecientes a la esfera del actuar, sino pautas escogidas del repertorio perteneciente a las experiencias del mantenimiento de la vida — la "labor"—, o, como desarrollaremos a continuación en el caso de la filosofía política platónica, la fabricación de objetos —el "trabajo" o poiesis.

\section{2.}

El rédito platónico permanente que extendió sus frutos a lo largo de la historia de la filosofía política fue, según se desprende de la comprensión arendtiana, la conversión de la política en una técnica de fabricación de la organización humana. La filosofía política puede definirse como una metafísica de los asuntos humanos, dispuesta en torno a las necesidades inherentes al hombre, y, por lo tanto, hostil hacia los fenómenos humanos salpicados de pluralidad. Al partir de, y acabar en, el hombre, al procurar instaurarse como técnica de la construcción o modelado de una comunidad humana organizada en torno a fines biológicos o filosóficos - mas nunca propiamente políticos - las teorías políticas se definieron, desde Platón, por su condición de "teoremas" de la pura dominación (Arendt 1996, p. 53), del sometimiento de un material en principio indomeñable a los principios de gobierno idóneos. Así, según la autora, Platón "no se interesa por el poder" (Id. p. 35), que refiere a las relaciones multívocas generadas en el espacio abierto por una pluralidad, sino al gobierno o dominio capaz de conducir a unidad, de acuerdo con la esencia, a lo "aparentemente" distinto. La organización, en este respecto, constituye la promesa de superación de la pluralidad, "de tal forma que los muchos se convierten en uno" (Ibid.). Desde la "perspectiva de eternidad" ofrecida por la esencia, la pluralidad del mundo humano es evaluada como el verdadero obstáculo para los fines del hombre, ya que se interpone e interfiere en la realización de su plena soberanía, de su libertad interpretada como capacidad de ordenar y construir una realidad que se ajuste mansamente a lo proyectado por la esencia. El sendero metafísico iniciado por Platón, y duradero en los pliegues de la entera historia de la filosofía, reiteró una y otra vez la sumisión de la política a los imperativos desprendidos de la idea de hombre o la esencia humana, y hubo de forjar una teoría política que, desatendiendo la dinámica inmanente de la pluralidad, ofreciera un utillaje extrínseco a ésta que operara la imposición de un orden orgánico o de automatismo capaz de propiciar el funcionamiento unitario de la ciudad, de forzar su aglutinación en torno a "fines" prestablecidos por el ámbito trascendente de la esencia. Por esta razón, la política sufrió 
tradicionalmente una amputación de su modo expresivo fundamental, la asamblea de agentes libres e iguales, para ser estructurada de acuerdo con imperativos técnicos de construcción y funcionamiento. La racionalidad técnico-metafísica, de este modo, significó para la política un reordenamiento integral, una inversión que desplazó su problemática del terreno del poder — la relación entre fuerzas de composición variable y contingente, los riesgos y promesas emergentes de la acción en común - al de los modelos de conformación de un funcionamiento orgánico, unificado y cuasi-natural. El problema central de la filosofía política fue siempre, de esta manera, el del sometimiento de la pluralidad, ya sea al todo, la colectividad organizada, ya al individuo aislado y sus fines, como ocurre en la teoría liberal moderna. Colectivismo e individualismo encuentran su identidad, de acuerdo con Arendt, en la común anulación del hecho de la pluralidad.

Platón, en definitiva, inauguró lo que Arendt denomina la afinidad del filósofo y el tirano —aunque fuera el tirano "filosófico" guiado por la contemplación de lo verdadero- ya que tendió a representar el entero campo de lo político como el material sobre el que un artesano o fabricante ejerce una violencia técnica conducente a la transformación de lo informe en objeto (Cf. Arendt 1996, p. 44). La maniobra metafísica de conversión de la acción — generada en el seno de una pluralidad de agentes - en fabricación, que puede ser efectuada por uno solo, proyecta su sombra sobre toda la historia de la política occidental, siendo asimismo una nota característica del siglo XX y, podríamos afirmar, del tiempo transcurrido desde la muerte de la pensadora hasta nuestros días. Las consecuencias inquietantes de esa conversión pertenecen por propio derecho a la situación política del día de hoy, y ponen sobre la mesa la pregunta acerca de la viabilidad y dirección a tomar por unas formas de organización política dirigidas de manera creciente al logro de la eficiencia técnica y económica: “(...) si la política es un asunto del hombre y de la constitución racional del Estado, sólo la tiranía puede producir buena política” (Ibid. Subrayados de la autora). El "experto", en este sentido, es la figura en la que converge la entera historia de la metafísica occidental en tanto extiende sus resortes hacia el terreno de los asuntos humanos, y supone la efectiva clausura del espacio público-político y su movilización en vistas a resultados de naturaleza técnica.

Arendt pone de manifiesto que Platón reformuló la problemática de la política, principalmente, desde el modelo de la fabricación de objetos, de tal manera que las metáforas productivistas —establecidas poderosamente como sustento de su ontología - le permitieron pensar los asuntos humanos como una esfera despojada de la complejidad e imprevisibilidad que le son inherentes, concibiéndola como la construcción de un súper-objeto dependiente de la sola pericia y el saber de un 
artesano experto, el "político". El desplazamiento de la articulación interna de la praxis por parte de las categorías pertenecientes a la poiesis se descubrió, en fin, en manos del exuberante pensamiento de Platón, como la estrategia de desactivación y redefinición de la política capaz de rendir más frutos. La metáfora que reunió al político-artífice con el cuerpo político, pensando éste como un material puesto a su disposición para modelar la "obra de arte total" — la ciudad o el Estado_manifestó ya tempranamente un poder de fascinación tan penetrante que se reveló incomparable en cuanto a la influencia y generación de efectos se refiere. La filosofía política, según se desprende del pensamiento de la autora, nació en esa poderosa metáfora platónica, y todo su devenir — desde la Grecia platónica hasta la época moderna- está gobernado por su irresistible embrujo. No ha habido, en el campo del pensamiento político, un conjunto de metáforas más incontestado, más rico en consecuencias y variaciones, más persistente que el de la política como empresa de construcción de la comunidad y el espacio político como taller del artesano.

En vistas de lo anterior, puede señalarse que la clave de bóveda de todo el edificio de la filosofía política platónica, en lo que tiene de inaugural para la tradición occidental, se identifica, pues, por la conversión de la acción y la esfera política a la que pertenece en una forma más de poiesis, y, por lo tanto, de techné, su modo particular de desvelamiento o verdad (Cf. Aristóteles 2001, pp. 185-188).

3.

El problema político al que procuró ofrecer respuesta la filosofía política en su fundación — en Platón — fue el de la inexistencia de la autoridad en la agitada práctica política de las ciudades griegas (Cf. “¿Qué es la autoridad?”, Arendt 1996, p. 165). La carencia de una instancia de autoridad que sí existía en el resto de actividades humanas — la vida doméstica, el arte, la producción técnica de objetos- parecía condenar a la esfera de los asuntos humanos a una incesante variabilidad e inseguridad que a menudo se hacían patentes en la forma de violencia despiadada, de envidia y ambición desatadas bajo la forma de la emulación no sometida a medida, de guerras interminables entre poleis, de esclavitud e iniquidad irreparables. A pesar del ensalzamiento de los aspectos nucleares de la vida política griega, Arendt no deja, aunque sea ocasionalmente, de recordar la realidad trágica de lo político en el marco de las democracias helenas. Según esta lectura, lo que inclinó a Platón a la búsqueda de una solución definitiva a los asuntos políticos fue su extremada sensibilidad — propiciada en gran medida por la muerte de Sócrates - ante la tragedia constantemente avivada por las rencillas y fragilidades 
del acontecer político. Si la filosofía política se configura en sus manos como una teoría de la dominación, si su objetivo último es desplazar el poder abierto de la multitud por un gobierno fundado filosóficamente, el significado no cabe hallarlo en una especie de furor utópico fundamentalista, sino en la voluntad de conducir lo caótico y peligroso a un orden capaz de asegurar la vida humana y sus más altos fines filosófico-contemplativos. A la búsqueda de modelos posibles de ordenación del espacio político, Platón no pudo más que dirigirse a las otras esferas de actividad humanas en las que el decurso de sus procesos no se veía salpicado de la futilidad y el riesgo que sí existía en el ejercicio político de la acción, esto es, a esas esferas de la vita activa en las que, de hecho, sí existían instancias de autoridad que conjuraban el riesgo de la violencia y el tumulto. Platón buscó el modelo de una autoridad benévola (Cf. Platón 1986, pp. 83-84) en los terrenos ajenos al político que estaban disponibles a su observación —el espacio doméstico de los procesos aseguradores de la vida, el ejercicio de las técnicas y el arte de producir-y así creyó poder asegurar un desenvolvimiento de los asuntos comunes no adherido a la sola potencia física de la violencia, pero tampoco al albur de las opiniones y la persuasión, sino guiado por una jerarquía reconocida al unísono tanto por el que ordena como por el que obedece, y fundada en la posesión del conocimiento adecuado.

Las estrategias platónicas destinadas a introducir formas de autoridad en el espacio incierto de la acción política son descritas por Arendt con detenimiento y perspicacia, observando como horizonte de sentido la desactivación de las incertidumbres a que los hombres son abocados en el ejercicio de una praxis carente de fines, de soberanía, ingobernable por la condición de pluralidad en que se realiza y perteneciente sin resto al ámbito de las apariencias. El magisterio del filósofo ateniense se reveló especialmente productivo en este encontrar un sustituto a la acción, en este fundir y redefinir la esfera de existencia política humana alejando los atisbos de indeterminación que despuntan en toda praxis y conformando un terreno que, en su previsibilidad y plena inteligibilidad eidética, se reorganiza de acuerdo con una afinidad esencial con respecto a los procesos calculables de fabricación. Frente a la apertura del espacio-entre de la política, aquel espacio del ágora o la asamblea cuyo sentido es articulado por la presencia de una pluralidad o multitud cuya acción concertada no obedece a reglas técnicas, de manos de Platón surgió una superficie transfigurada, un recinto de producción dotado de fines precisos y gobernado por las metáforas de la efectividad, la autoridad, la eficiencia y la soberanía. Surgió la nueva imagen de una política despojada de categorías políticas, una política a-política que constituyó el acariciado ideal de buena parte de la especulación filosófica tradicional. La ironía, que no falta en buenas dosis 
cuando contemplamos la serie histórica iniciada en el pensar de Platón, es que, si bien el pensador ateniense creyó posible esquivar los males de la política a través de la desactivación efectiva de ésta, su esfuerzo desembocó — aunque fuera inintencionadamente - en la multiplicación y engrandecimiento de la opresión y la tiranía. La supresión de lo político, como se reveló, en última instancia, en la sociedad y los totalitarismos modernos, no produjo la extinción de los males latentes en su seno, sino su ensanchamiento, su distorsión amplificada y ya liberada de los remedios que sólo la acción puede establecer ante sus riesgos: "Bajo este punto de vista, en lugar de una abolición de lo político obtendríamos una forma despótica de dominación ampliada hasta lo monstruoso" (Arendt 1997, p. 50).

4.

El elemento central que Arendt distingue en la configuración del saber técnico, elemento del que la acción o praxis carece por completo, es la soberanía, es decir, la capacidad del fabricante de guiar y tutelar todo el proceso, desde su comienzo hasta la compleción del objeto final. El horizonte que, según ella, movió a Platón a reemplazar el modelo abierto de la política por una nueva techné dedicada a la construcción, ordenamiento y gestión de los asuntos humanos fue, entonces, la consecución de un saber de lo político que introdujera en su seno el dominio que el técnico o el artesano poseen desde un principio sobre su obra, de modo que fuera posible desterrar la indeterminación que convierte a la acción en frágil, impredecible e ingobernable. Sustituyendo la acción por un hacer fundado en el conocimiento técnico, Platón contemplaba la posibilidad de desactivar las consecuencias dolorosas de un actuar que se realiza generalmente en situación de ceguera acerca de los efectos e implicaciones de lo realizado, y que sólo alcanza una seguridad demasiado inestable y falible a través de remedios tan frágiles como la promesa y el perdón ${ }^{7}$.

El repertorio de las metáforas que sirvieron a Platón para reorientar la esfera de la acción hacia la del saber y el ejecutar técnicos es, por sí mismo, elocuente: la política es un "arte de tejer" (Platón 1988, p. 606); el gobernante es el "piloto" de una nave, y "el piloto, en sentido estricto, es gobernante de marineros, y no un marinero" (Platón 1986, p. 83). Los momentos de la acción, convenientemente

\footnotetext{
${ }^{7}$ Acerca de la promesa y el perdón, entendidos como remedios ante la impredecibilidad y falta de soberanía de la acción, véase: Arendt 1998, especialmente pp. 236-247 (Arendt 2005, pp. 255-265).
} 
desarticulados y troceados para facilitar la introducción de una autoridad extrapolítica, dieron finalmente en la básica distinción platónica que gobierna la esfera toda del hacer y convierte a toda actividad humana en aplicación de principios teóricos: la distinción entre aquel que sabe y el que ejecuta, entre el filósofo —el "verdadero político" o poseedor de la techné politiké- y la muchedumbre; entre el gobernante y el súbdito; o, en términos actuales, entre el experto y el simple ciudadano laborante: “(...) a quienes participan en todos estos regímenes políticos, excepción hecha del individuo que posee la ciencia, hay que excluirlos, dado que no son políticos sino sediciosos" (Platón 1988, p. 604).

Situado ante la "triple frustración de la acción", Platón ingenió un poderosísimo arsenal teórico cuyo objeto se tradujo en la anulación de la acción y la ocupación de su ámbito por las actividades humanas sometidas a cálculo y soberanía. La forma de disolver la praxis en la poiesis, y, por lo tanto, de reemplazar la indeterminada libertad política por la libertad soberana del fabricante, consistió principalmente en distinguir en la acción, como en la fabricación, el saber qué del hacer, e identificar la acción misma sólo con este último momento, un "llevar a cabo" entendido como ejecución, como aplicación de un saber previo y separado; al igual que en la poiesis se pueden distinguir los dos momentos precisos y constitutivos — la idea pensada que sirve de modelo o paradigma y la fabricación efectiva "con las manos", que modela en la materia inerte lo presente en aquéllaPlatón concibió la acción en la pólis como un hacer que completa y realiza lo ya pensado con anterioridad, y que puede ser ejecutado por quien recibe de otro la idea directora. De la misma manera que la parte racional del alma, "que confía en la medición y el cálculo" (Platón 1986, p. 470), se constituye como parte rectora, órgano capaz de gobernar al cuerpo entendido como materia cuasi-inerte, el saber -basado en el conocimiento de la trama ontológica de las formas o ideas- ha de monopolizar en la ciudad la facultad de iniciar, señalando el modelo precedente de lo por hacer y arrancando a la acción su carga imprevisible de incertidumbre y desconocimiento de consecuencias.

5.

En beneficio de una concepción de la política plegada a los imperativos de la fabricación el mismo Platón plasmó la configuración definitiva de las ideas o

\footnotetext{
${ }^{8}$ Es decir: impredecibilidad, irrevocabilidad y carácter anónimo de sus autores (Cf. Arendt 1998, p. 220).
} 
formas (eidoı) con el fin de adecuarlas a sus fines más concretamente políticos, y transformó su posición y relevancia de acuerdo con los intereses de fundación de su original techné politiké. Platón, dice Arendt, "had taken the key word of his philosophy, the term 'idea', from experiences in the realm of fabrication" (Arendt 1998, p. 225) ${ }^{9}$. En una lectura presumiblemente influida por la tesis de Heidegger acerca de la esencia de las ideas platónicas, la pensadora judía establece un hiato decisivo entre el semblante del eidos en los diálogos platónicos no estrictamente políticos y su introducción — de consecuencias perdurables—en la pólis, efectuada en obras como la República o el Filebo, en las que el centro de su interés se revela como la producción de un modelo director de saber político y ético ${ }^{10}$. Con el fin de habilitar una fuente de autoridad externa e inmutable, independiente del tornadizo espacio aparencial de la política, Platón realizó una transformación capital en su concepto del eidos, que le llevó de entenderlo primeramente como aquello capaz de "iluminar" el ser a definirlo como medida absoluta aplicable al cálculo y fijación de lo que por sí — lo perteneciente al mundo del aparecer — tiende a la fluidificación y la huida constantes. Arendt, en esta dirección, señala cómo el carácter original de las ideas platónicas, la irradiación luminosa que permite al pensamiento la contemplación de la esencia, fue desplazado en relación con la búsqueda del modo de intervención del filósofo en la realidad política; mientras en el Banquete la clave de bóveda de todo el sistema de las formas es la idea de belleza, dotada del poder iluminador y revelador al que aspira allí el filósofo, en la República la cúspide de las ideas es el Bien, que posee la dimensión de aplicabilidad y, por lo tanto, sirve de manera idónea al propósito de hacer de las formas algo políticamente utilizable (Cf. Arendt 1990b, p. 77). "Bueno", como recuerda Arendt, significa en griego "bueno para" o "adecuado", por lo que su preeminencia entre las ideas reforma el carácter entero de éstas para conducirlas a la aplicación y el uso (Ibid.) ${ }^{11}$. Las

9 “ (...) había obtenido la palabra clave de su filosofía, la 'idea', de las experiencias en la esfera de la fabricación” (Arendt 2005, p. 246).

${ }^{10}$ La ruptura interna de las obras platónicas, que permite observar una variación crucial en la esencia y función de las ideas, no sólo fue señalada por Arendt, sino que ha sido una importante fuente de especulación en torno a la filosofía del ateniense (por ejemplo: Ross 1989, pp. 284-288).

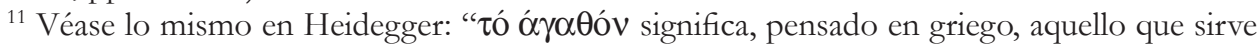
o es útil para algo y que vuelve a algo útil y servible". ("La doctrina platónica de la verdad", Heidegger 2000, p. 190). En Platón, por su parte: “(...) la idea del Bien es el objeto del estudio supremo, a partir de la cual las cosas justas y todas las demás se vuelven útiles y valiosas" (Platón 1986, p. 327). 
ideas abandonaron, de esta manera, su condición desocultadora para adoptar la de criterios de medida y corrección, principios unívocos de autoridad. Tal y como Heidegger había apuntado, la verdad filosófica, en Platón, se transformó en corrección, y las formas en criterios de medición de la armonía idónea para reunir en unidad las cosas y propiciar su juntura.

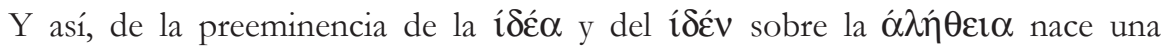
transformación de la esencia de la verdad. La verdad se torna ó $\rho \theta$ ó $\tau$ ऽ, corrección de la aprehensión y del enunciado (Heidegger 2000, p. 192).

No obstante, Arendt, a diferencia de su maestro, encontró la razón última de esta conformación de las ideas en el problema político que el ateniense se propuso resolver, antes que en otro tipo de razones abstractas como las esgrimidas por el filósofo alemán. La incomprensión heideggeriana del ámbito de lo político fue, quizás, la responsable de esta "ceguera". Al fin y al cabo, Arendt quiere iluminar la problemática que Heidegger no supo o quiso descubrir, quizás porque, tal y como ella afirmó, él mismo compartía los prejuicios filosóficos comunes acerca de la esfera de los asuntos humanos (Cf. Arendt 1996b, pp. 106-108). El problema central que afronta Platón, según esto, más que el de asegurar la unidad de las cosas, es introducir el principio de unidad en la ciudad, reconducir las inestables relaciones políticas al orden unitario y permanente que sólo una entidad externa puede asegurar. De esta manera, la ontología platónica plasmada en la teoría de las formas estaría, en origen, atravesada por intereses eminentemente políticos, y el carácter técnico de las ideas -que hace que el ser tome en Platón, como advirtiera asimismo Heidegger, la configuración de producto- procede, en tal coyuntura, de la voluntad de conformar técnicamente la unidad de la pólis. Según la apreciación arendtiana, en suma, el problema capital latente en toda la articulación filosófica de las ideas es el de la política y la viabilidad de la vida humana en común. La búsqueda de una autoridad capaz de fijar el voluble ámbito de lo humano condujo al filósofo ateniense a transformar la esencia misma de las ideas para convertirlas en "modelos en medio del torbellino" (Arendt 2006, p. 293), en criterios de corrección análogos al arquetipo según el cual los objetos de la técnica son fabricados y que constituye la medida a la que éstos han de adecuarse. La solución platónica al problema político, pues, consiste en redefinir todos los problemas y riesgos que afectan a su espacio como problemas técnicos dependientes de la dispersión de su materia, un material que ha de ser llevado a unidad a través de la confección de un objeto que se adecúe —como en el caso de las cosas fabricadas - a la determinación de unidad recogida en el prototipo ideal. 
Sobre la idea: las ideas platónicas, concebidas originariamente como objetos de contemplación y experimentadas en la producción, se convierten en estándares, reglas y 'medidas' por primera vez cuando son aplicadas a la acción. Por tanto, entran ya pervertidas y desnaturalizadas en la moral y la política. Dicho de otro modo: originariamente la idea no había de ser nunca la 'idea del bien', sino la idea de la cama; porque se necesitaban $\mu \varepsilon ́ \tau \rho \alpha$ en lo político, se 'inventó' la idea del bien (Arendt 2006, pp. 438-439).

Las ideas platónicas constituyen los recursos más potentes que, en la desoladora percepción que el filósofo ateniense se forjó del campo de lo político, ofrecen respuesta al peligro contenido en la convivencia humana; ellas son las que, en el seno de la filosofía política, insertan con contundencia un principio extra-político en medio del ámbito de los asuntos humanos para conducirlo a gobernabilidad ${ }^{12}$; ellas las que introducen la posibilidad de una autoridad que sirva de medida para el conjunto de decisiones de las que depende la pervivencia de la pólis; ellas, en definitiva, las que permiten el hecho de la obediencia y terminan con la isonomía inmanente a la esfera de la acción pública. Al establecer un arquetipo como fin de toda acción común, Platón cree, según la lectura de Arendt, encontrar remedio contra la relatividad de los asuntos políticos, sujetando su predio a medida, asiendo su rostro proteico de acuerdo con las herramientas más simples y efectivas de fijación: medir, contar, pesar (Cf. Arendt 2006, p. 229) ${ }^{13}$. Por esta razón, el político no es ya el ciudadano capaz de iniciativa, capaz de acción y palabra, sino que, como liberado de la "caverna" de las apariencias, sería más bien un técnico que supera el engaño a través del cálculo ${ }^{14}$. Por eso, de la misma manera, la maniobra de Platón situó como concepto político principal, no ya la amistad —a la que todavía

${ }^{12}$ En Patôcka, pensador tan influido por el pensamiento de Arendt, podemos encontrar la misma conclusión: "The idea is to be the measure we need in order to know what is good. The entire platonic problematic stems from our needing some kind of life measure, which should be analogical to the measures of geometry, which are the conditions for measuring things that are not geometrical" ("La idea existe para ser la medida que necesitamos con vistas a conocer lo que es bueno. La entera problemática platónica surge de muestra necesidad de alguna medida para la vida, que habría de ser análoga a las medidas de la geometría, que son la condición para poder medir las cosas que no son geométricas”) (Patôcka 2002, p. 217).

${ }^{13}$ Véase en Platón: "Y el medir, el contar y el pesar se han acreditado como los más agraciados auxiliares para evitar esto, de modo que no impere en nosotros lo que parece mayor y menor, más numeroso o más pesado, sino lo que calcula, mide y pesa” (Platón 1986, p. 469).

14 "Pretende que, al pintar las cosas tal como aparecen, los pintores explotan nuestra propensión natural a ser engañados por estos proyectores de sombras; $y$ dice que las defensas que poseemos contra esta propensión son técnicas tales como medir, contar y pesar" (Crombie 1979, p. 90). 
en el Banquete caracterizó como motor de la cohesión política, tal y como habían hecho Sócrates y, después de él, Aristóteles (Cf. Arendt 1990b, pp. 82-84) - sino la justicia, una justicia entendida como el conocimiento de la proporción y la medida matemáticas aplicables a los objetos elaborados a través del trabajo, indiferente hacia el hecho de la pluralidad, y de la que Arendt afirma que "no tiene nada que ver con la política", ya que, a diferencia de aquélla, "es posible también en la reconditez absoluta" (Arendt 2006, p. 218). La anegación de la política en la técnica, por último, se pone de relieve en la concepción de aquélla como un conocimiento análogo al de ésta, ya que el conocimiento mismo responde a un modelo eminentemente técnico, tal y como comunican las metáforas e imágenes empleadas por Platón a la hora de su descripción ${ }^{15}$. Caracterizada nítidamente frente a la amistad socrática, la justicia platónica descubre su índole de conocimiento técnico acerca de la repartición organizada de funciones, conocimiento que disuelve la pluralidad en un objeto unitario, proporcionado y orgánico.

6.

La conversión de la política en un hacer técnico arrastra tras de sí la reconfiguración decisiva de sus estructuras de sentido. La actividad política, en su redefinición platónica, vendrá a ser definida por el sometimiento a las categorías centrales del trabajo y la fabricación, las de "medio" y "fin". En el caso específicamente platónico, el fin superior al que ha de apuntar el despliegue de la política es el de asegurar la más alta posibilidad de existencia humana, la vida filosófica, y, por ello, la intervención política exigida en la República al filósofo como una carga no se concibe en relación a un significado propiamente político, sino exclusivamente filosófico: el filósofo, para asegurar su actividad contemplativa, necesita de una "política razonable" (Cf. "El final de la tradición", Arendt 2008, p. 119), necesita no permitir que le gobiernen los "peores" 16 , y con vistas a ello

\footnotetext{
15 Aquí, a su vez, se pone de relieve cómo la filosofía entera de Platón está invadida por el modelo técnico. El concepto de conocimiento mismo, centro focal de toda su concepción, está, en sus dimensiones más conspicuas, tomado del ámbito del trabajo, y sus imágenes decisivas refieren al uso y fabricación de útiles: "Y la excelencia, belleza y rectitud de cada instrumento, ser viviente o acción, ¿están referidas a otra cosa que al uso que les corresponde por naturaleza o que fue tenido en cuenta al fabricarlas?” (Platón 1986, p. 467).

16 "Por eso es necesario que se les imponga compulsión y castigo para que se presten a gobernar; (...) el mayor de los castigos es ser gobernado por alguien peor, cuando uno no se presta a gobernar" (Platón 1986, p. 90).
} 
habrá de convertir a la política misma en una labor de corte filosófico. Así, en el Político y el Crátilo, el ateniense asigna un mismo tipo de actividad — la de trenzar adecuadamente un tejido- al político y al filósofo, actividad que consiste en la práctica de un saber acerca de las proporciones adecuadas en las que puede mezclarse un material dado con vistas a su unificación. Al escoger la metáfora del arte de tejer como descripción de la labor de ambos, se descubre patentemente la indiferenciación de sus identidades, la mismidad de sus procedimientos y propósitos. La política sólo puede ser entendida, para despojarla de su carga amenazadora, como rama de la metafísica ${ }^{17}$. Platón inaugura, de esta manera, un modelo reiterado de pensamiento acerca de la acción política, un modelo que pervive a lo largo de toda la tradición y se agudiza en la época moderna: la política es un "mal necesario" y sólo ha de justificarse como panoplia de medios capaces de alcanzar bienes externos a ella, sea la vida filosófica, la santidad o la salvaguarda de los intereses privados ${ }^{18}$.

La política fue así tradicionalmente aprisionada por una doble cobertura que la degradó sustancialmente: por "abajo" se convirtió en producto de la necesidad y sus urgencias; por "encima" se supeditó a la consecución de fines superiores y extrapolíticos. El interés supremo de la política fue así reformulado por Platón, disponiendo la acción política como la hechura de los medios capaces de cubrir las necesidades vitales, por un lado, y cancelar la política misma en actividades superiores, por el otro. La filosofía política, en este sentido, es pensada por Arent como la demanda de una organización de la ciudad que facilite su conversión en un medio más para la producción de bienes no políticos: la política se torna en medio "para otra cosa" que no es la política misma. El campo político, de esta forma, es pensado, no ya como espacio o apertura, sino como material de construcción: la filosofía política platónica se dibuja como un estricto materialismo (Cf. Arendt 2006 , p. 312) en el doble sentido de que se instala en el terreno de la técnica de dominio sobre los cuerpos —está "determinado por lo meramente corporal"

\footnotetext{
${ }^{17}$ Los pasajes en los que se compara el arte del político, por un lado, y el saber del filósofo dialéctico, por otro, con el arte de tejer se encuentran, respectivamente, en Político y Crátilo: Platón 1988, pp. 606 y ss., Platón 1983, pp. 372-377.

${ }^{18}$ Lo que, por otro lado, muestra en el neoliberalismo moderno una sospechosa afinidad con las tiranías clásicas: "Los tiranos, si conocen su cometido, pueden ser 'amables y suaves en todo', como Pisístrato (...); sus medidas pueden ser muy 'poco tiránicas' y beneficiosas a los oídos modernos (...). Sin embargo, todos tienen en común el destierro de los ciudadanos de la esfera pública y la insistencia en que se preocupen de sus asuntos privados y que 'sólo el gobernante debe atender los asuntos públicos"' (Arendt 1998, p. 221) (Arendt 2005, p. 243).
} 
(Ibid.) - , por un lado, y entiende la agregación de éstos en la ciudad como la de un material bruto con el que producir fines superiores, por otro. La pólis, en el seno de esta nueva concepción política, es tomada por las categorías instrumentales, insertada en la cadena de medios y fines a través de la cual el trabajo moviliza y se apodera de lo mundano. Esta es la contribución revolucionaria de la filosofía de Platón al pensamiento de lo político, y será fijada como marco de comprensión de la acción política a lo largo de la generalidad de la tradición occidental ${ }^{19}$. La comunidad política ya sólo puede ser entendida como el producto de una fabricación consciente guiada por el conocimiento de ideas extrapolíticas, pero al ser constituida como fin u objeto de producción se aboca a su vez a ser degradada a mero medio a través del cual alcanzar otras cosas que se representan como de más alto valor, dado que la aplicación de las categorías de medio y fin significa, según Arendt, el sometimiento a la regla que dice que todo fin se convierte, a su vez, en medio para la producción de cosas posteriores ${ }^{20}$.

Adecuándose a la horma de un saber técnico, la política y su objeto adoptaron en la audaz configuración platónica una forma sustancialmente diversa a la asumida por Arendt como consistencia fenomenológica de su ejercicio. Si ella advirtió en ciertos rasgos de la pólis democrática griega una aparición genuina de rasgos definitorios de la acción humana, tal y como también los advirtió en las repetidas eclosiones revolucionarias de la época moderna, también percibió la magnitud del frontal ataque platónico contra una política conformada como autoorganización de los iguales y libre aparecer de unos y otros. La inmensa desconfianza de Platón hacia el poder —entendido precisamente como esa autoorganización de la pólis aglutinada en torno a la acción y la palabra libres_-, su temor ante el desorden suscitado por acciones ni regladas ni gobernadas por fines establecidos racional y técnicamente, le llevaron a procurar constituir un saber mediante el cual ese "gran animal” al que asimiló al pueblo (Cf. Platón 1986, pp. 308-309) pudiera ser sujetado a principios y guías sólidos, y a instituir criterios teleológicos capaces de cerrar la apertura de la acción a lo indeterminado e incierto. Con ello, el filósofo ateniense pretendió evitar el deslizamiento — tan repetido en la agitada experiencia política

\footnotetext{
${ }^{19}$ En realidad, según Arendt, el pensamiento occidental en sí mismo está desvalido fuera de las categorías de "medio" y "fin" (Cf. Arendt 2006, p. 46).

${ }^{20}$ La lógica de las categorías instrumentales es desarrollada por la autora en: Arendt 1998, pp. 153-159 (Arendt 2005, pp. 178-183). En este lugar podemos leer: "Es decir que, en un mundo estrictamente utilitario, todos los fines están sujetos a tener breve duración y a transformarse en medios para posteriores fines" (Id. p. 178).
} 
griega - de la disputa política hacia la violencia abierta, pero al precio, afirma Arendt, de depositar la violencia misma como rasgo determinante del quehacer político, ya que la introducción de fines en el horizonte de la práctica política significa necesariamente — tal y como ocurre en los procesos de fabricación- la admisión de cualquier medio, sea éste de la naturaleza que sea.

El intento de evitar la disolución anárquica de la convivencia política condujo a Platón a consumar, más que a evitar, la unión de política y violencia bajo la pretensión de que sólo guiada por imperativos técnicos dejaría ésta de ser una amenaza para la comunidad - y, especialmente, para el filósofo- y se regiría por dictados razonables y benévolos. La asimilación de la política a la producción introdujo, por lo tanto, su conformación en torno a una violencia correlativa, de tal manera que la tradición occidental conservó la noción nuclear de que el problema del poder político es el de la posesión de los medios de la violencia, y el Estado el detentador "legítimo" de su monopolio ${ }^{21}$.

\section{CONCLUSIÓN}

Como resultado de todo lo anterior, es posible afirmar que, a pesar de percibir en la obra platónica una complejidad no reducible a fórmulas unívocas o esquemáticas, Arendt logra convincentemente reunir el núcleo del significado de la filosofía política de Platón alrededor de la sustitución de la acción incierta y enmarañada, dada entre una pluralidad de iguales-diferentes, por la actividad artesanal y técnica. Las perplejidades de la acción política son, de este modo, canceladas en favor de la previsibilidad presente en los procesos de fabricación, donde se distinguen con nitidez el ámbito de los medios y el de los fines, de manera que los hombres son reformulados como material bruto a partir del cual pueda levantarse la pólis, no ya como tráfago indomeñable de acciones y palabras, sino como producto de un saber técnico preciso. La ciudad es, de esta manera, atravesada por una ruptura epistemológica decisiva que separa a aquellos que saben —los "verdaderos" políticos, los filósofos - de los que, apartados del conocimiento proyectivo y técnico, ciegos ante el resplandor del eidos, encuentran su lugar en la aplicación de lo señalado por aquéllos. Esta fractura del campo de las cosas humanas, marcada por la posesión del saber acerca de los asuntos

\footnotetext{
${ }^{21}$ Tal y como estableció Weber en su tan célebre definición del Estado: “(...) Estado es aquella comunidad humana que, dentro de un determinado territorio (...), reclama (con éxito) para sí el monopolio de la violencia física legítima" ("La política como vocación”, Weber 1969, p. 83).
} 
humanos, permite, entonces, convertir la política en asunto de uno o unos pocos (Cf. Platón 1988, pp. 579-580), a la vez que posterga el lugar y significado de la praxis hasta convertirla en mera obediencia y aplicación de principios dictados por una autoridad ajena al mismo actuar. Tan fundamental resulta, según defiende la autora alemana, esta crucial innovación platónica, que sus resultados se extienden por toda la política occidental hasta llegar al momento actual, en el que la política es representada como asunto de expertos, de poseedores de un saber técnico que agota los márgenes de lo político y han de ser escuchados y obedecidos convenientemente, de manera que la misma definición de democracia se ve profundamente alterada, ya que "Wherever knowing and doing have parted company, the space of freedom is lost" (Arendt 1990, p. 264) 22 .

Por último, como resultado de este condensado periplo, cabe preguntarse por el alcance y la significación real de la crítica arendtiana, pero también por los límites que la cierran y obligan a una continuación del pensar acerca de la acción política en las condiciones contemporáneas:

En primer lugar, Arendt supo enunciar con claridad uno de los más poderosos interrogantes que pesan sobre la actual práctica de lo político, y que la ligan a su fundación platónica: ¿cuál es el precio de la sujeción de la política a la fabricación? ¿Cuál es el riesgo presente en la eliminación del carácter espontáneo de la acción? En última instancia, el riesgo último que es posible entrever en todo el relato arendtiano es el reinado de la tecnocracia, la burocracia - tal y como se consuman en el mundo moderno - y, en última instancia, el totalitarismo, último avatar de una historia política occidental presidida por la alegoría platónica de la caverna. La conversión platónica de la acción en fabricación, tan esforzada como exitosa, imprimió una huella extraordinariamente duradera a toda la descendencia intelectual del filósofo ateniense, que, atravesando los casi dos mil quinientos años que median, alcanza hasta la culminación de la edad moderna y se vierte — de forma siniestra - en el nacimiento de las ideologías políticas empeñadas en la "construcción" o "fabricación" de un "hombre nuevo" y una sociedad renovada, pulimentada, expurgada de todo resto de indeterminación e incertidumbre. Esto no quiere decir que Arendt responsabilice a Platón del holocausto judío o el terror estalinista, sino que la desarticulación platónica de la política, su redefinición en términos de conocimiento técnico, abrió la posibilidad de alcanzar su anulación absoluta en tanto que política —es decir: en tanto que pluralidad humana — tal

\footnotetext{
22 "Siempre que se separa el conocimiento de la acción, se pierde el espacio de la libertad" (Arendt 2004, p. 365).
} 
y como la quisieron realizar los totalitarismos modernos. Una política como la propuesta en el proyecto platónico descansa, según Arendt, en la profunda desconfianza y el deseo de eliminar la acción junto a todas sus incertidumbres, pero, a la vez, elimina la posibilidad de esgrimir los únicos remedios válidos para contrarrestar los peligros del ámbito político, que son los pertencientes al campo mismo de la acción.

Por otro lado, Arendt, al construir una imagen de la acción exenta de todo rasgo técnico o estratégico, forjó un concepto cuya validez ha de ser problematizada a la luz de una realidad en la que apenas se dan elementos puros. Si bien ella se preocupó por aislar los rasgos esenciales de la acción con el fin de impedir su asimilación a formas diversas de actividad y garantizar con ello el sentido autónomo de la política, lo que le permitió revelar ciertas amenazas fundamentales para la pervivencia de la acción humana, su forja de un tipo ideal de política corre el riesgo de no responder a una realidad en la que las distintas actividades están de hecho disueltas en movimientos que las comprenden sin posibilidad de demarcación rígida. La distinción arendtiana de lo "político" y lo "social", es decir, de la esfera de la "aparición ante los otros" y la de las exigencias económicas, técnicas y vitales, posee el sentido de hacer sitio a la acción humana, de otorgarle un estatus propio y no dependiente, de evitar su conversión en mero medio instrumental. En esta dirección, la propuesta de Arendt ofrece a la mirada un amplio panorama de las amenazas que acechan en la anegación de la acción política en actividades guiadas por intereses extra-políticos. Pero, ¿en qué sentido puede defenderse la práctica de una política "pura", no contaminada por la presencia ineludible de aspectos e intereses que desbordan el campo de la sola "aparición ante los otros" y remiten al entreveramiento constante de lo político y lo "social"? El brillante esfuerzo arendtiano exige, en este sentido, una profundización del pensamiento acerca de las condiciones de posibilidad de la acción política en las condiciones presentes de vida, condiciones en las que lo que a la mirada se ofrece es una imbricación extrema de actividades, esferas, e intereses que hace difícil, si no imposible, una exacta separación entre lo político, lo económico o lo social. En este sentido, ya Habermas indicó los límites de la propuesta de Arendt al juzgar los réditos de su pensamiento, señalando también sus indiscutibles aportaciones:

(...) un estado descargado del tratamiento administrativo de las cuestiones sociales; una política purificada de las cuestiones de política social; una institucionalización de la libertad pública, independiente de la organización del bienestar (...) esto ya no es un camino practicable para ninguna sociedad moderna ("El concepto de poder en Hannah Arendt", Habermas 1975, p. 215). 
(...) por otra parte, Hannah Arendt insiste con toda razón en que la realización del bienestar no debe confundirse con la emancipación con respecto al dominio. (...) Tanto en el Este como en el Oeste el impulso revolucionario inicial se agota en los objetivos de una eliminación técnicamente eficaz de la miseria y del mantenimiento administrativo de un sistema de creciemiento económico exento de conflictos sociales ("La historia de las dos revoluciones", Habermas 1975, p. 204).

\section{Borja Lucena \\ IES Antonio Machado, Soria lugongora@yahoo.es}

\section{BIBLIOGRAFÍA}

AREndT, H. (1971): “Thinking and Moral Considerations”, Social Research, no 38:3, pp. 417-446.

- (1978): The Life of the Mind, San Diego-New York-London: Harcourt, Inc.

- (1990): On Revolution, London: Penguin Books.

- (1990b): "Philosophy and Politics", Social Research, no 57:1, pp. 73-103.

- (1996): Entre el pasado y el futuro. Ocho ejercicios de reflexión política, traducido por Poljak, A., Barcelona: Península.

— (1996b): "Heidegger octogenario", traducido por Bayón, J., Revista de Occidente, no 187, pp. 93-109.

- (1997): ¿Qué es la política?, traducido por Sala Carbó, R., Barcelona: Paidós.

- (1998): The Human Condition, Chicago-London: The University of Chicago Press.

- (2004): Sobre la revolución, traducido por Bravo, P., Madrid: Alianza Editorial.

- (2005): La condición humana, traducido por Gil Novales, R., Barcelona: Paidós.

- (2006): Diario filosófico, traducido por Gabás, R., Barcelona, Herder Editorial.

- (2007): "The Great Tradition. I. Law and Power", Social Research, n 74:3, pp. 713-726.

- (2008): La promesa de la política, traducido por Cañas, E., Barcelona: Paidós.

ARISTÓTELES (2001): Ética a Nicómaco, traducido por Calvo Martínez, J.L., Madrid: Alianza Editorial.

Crombie, I. M. (1979): Análisis de las doctrinas de Platón. 2. Teoría del conocimiento y de la naturaleza, traducido por Torán, A. y Armero, J. C., Madrid: Alianza Editorial.

FORTI, S. (2001): Vida del espiritu y tiempo de la polis, traducido por Romera Pintor, I. y Vega Cernuda, M. A., Madrid: Cátedra.

GranadA, M. A. (1994): "Agostino Steuco y la perennis philosophia", Daimon, n. 8, pp. 23-38.

Habermas, J. (1975): Perfiles histórico-politicos, traducido por Jiménez Redondo, M., Taurus: Madrid.

- (1988): Nachmetaphysisches Denken, Frankfurt: Suhrkamp. 
Heidegger, M. (2000): Hitos, traducido por Cortés, H. y Leyte, A., Madrid: Alianza Editorial.

LuCENA GÓngora, F. B. (2015): Hannah Arendt: la crítica de las ideologías como crítica de la filosofía politica, Tesis Doctoral, UNED.

PATÔCKA, J. (2002): Plato and Europe, traducido al inglés por Lom, P., California: Stanford University Press.

PlATÓN (1986): Diálogos IV, traducido por Egers Lan, C., Madrid: Editorial Gredos.

- (1988): Diálogos V, traducido por Santa Cruz, M. I., Vallejo Campos, A., Luis Cordero, N., Madrid: Editorial Gredos.

- (1983): Diálogos II, traducido por Calonge Ruiz, J., Acosta Méndez, F., Olivieri, F. J., Calvo, J. L., Madrid: Editorial Gredos.

Ross, D. (1989): Teoría de las ideas de Platón, traducido por Díez Arias, J. L., Madrid: Cátedra. WEBER, M. (1969): Elpolítico y el cientifico, traducido por Rubio Llorente, F., Madrid: Alianza Editorial. 